Brazilian Journal

of Chemical

ISSN 0104-6632

Engineering

Printed in Brazil

www.scielo.br/bjce

Vol. 34, No. 04, pp. 1191 - 1202, October - December, 2017

$($ (c) $)$ EY

dx.doi.org/10.1590/0104-6632.20170344s20160227

\title{
PARAMETRIC STUDY OF SWEETENING PROCESS OF SOUR GAS BY MOLYBDENUM OXIDE NANOPARTICLES
}

\author{
Amir Hosseini ${ }^{1}$ and M. Nabipoor Hassankiadeh ${ }^{1, *}$ \\ 'Production Department, Phases 9\&10, South Pars Gas Complex (SPGC), National Iranian Gas Company, Assaluyeh, Iran \\ *Corresponding author: Mojtaba Nabipoor Hassankiadeh, South Pars Gas Complex, Phases 9\&10, Assaluyeh, Iran, \\ P.O.Box:85391-311; Tel. :(+987731)317364; Fax: (+987731)317740; Email: mojtabanp@yahoo.com
}

(Submitted: November 7, 2015; Revised: May 22, 2016; Accepted: June 8, 2016)

\begin{abstract}
The purpose of this work is to study the application of nano-molybdenum oxide adsorbent in gas sweetening process. Experiments were made to evaluate the operating and geometrical parameters in the adsorption process. The process performance of $\mathrm{H}_{2} \mathrm{~S}$ removal from methane gas on molybdenum oxide nanoparticles was defined as the ratio of final concentration of $\mathrm{H}_{2} \mathrm{~S}$ on the initial concentration of $\mathrm{H}_{2} \mathrm{~S}$. The effects of operating conditions such as operating temperature, pressure, the size of nanoparticles, the amount of $\mathrm{H}_{2} \mathrm{~S}$ concentration in feed stream, feed superficial velocity, and the bed length were studied in this paper. Different temperature values $\left(65,75,85,87\right.$ and $\left.89{ }^{\circ} \mathrm{C}\right)$ and pressure values $(10,13,16$ and 19 bar) were applied on the adsorption bed with $19 \mathrm{~cm}$ length and $10 \mathrm{~cm}$ diameter. Two types of spherical and cylindrical nanoparticles were applied and the effect of different adsorbents diameters $(54,58$, $73,77$ and $83 \mathrm{~nm})$ on the process quality $\left(C / C_{0}\right)$ was investigated. Also, the effect of initial concentration of $\mathrm{H}_{2} \mathrm{~S}$ in the feed gas stream was surveyed. The optimum operating conditions for spherical and cylindrical types were the same, 16 bar and $85^{\circ} \mathrm{C}$. The adsorption capacity of $0.22 \mathrm{~g} \mathrm{H}_{2} \mathrm{~S} / \mathrm{g} \mathrm{MoO}_{2}$ and $0.19 \mathrm{~g} \mathrm{H}_{2} \mathrm{~S} / \mathrm{g} \mathrm{MoO}_{2}$ was achieved at the optimum conditions using nano-spherical and nano-cylindrical $\mathrm{MoO}_{2}$ sorbent, respectively. Applying in our study two adsorption isotherms, the Langmuir and Freundlich isotherms, analysis of variance displayed a high coefficient of determination $\left(\mathrm{R}^{2}\right)$ value of 0.989 for the Freundlich isotherm, indicating the satisfactory adjustment of the experimental data. The results can be interesting for related industries and can be applicable in process optimization.
\end{abstract}

Keywords: Parametric study, Sweetening process, Molybdenum oxide, Nanoparticle Adsorbent, adsorption isotherm.

\section{INTRODUCTION}

The natural gas (NG) extracted from independent gas wells usually contains a large percentage of methane gas, some quantity of ethane and a little quantity of other alkanes and small amount of impurities such as carbon dioxide $\left(\mathrm{CO}_{2}\right)$, nitrogen, hydrogen sulfide $\left(\mathrm{H}_{2} \mathrm{~S}\right)$ etc. (Mandal et al. 2004; Alie et al. 2005). Among the nonhydrocarbon components existing in $\mathrm{NG}, \mathrm{CO}_{2}$ and $\mathrm{H}_{2} \mathrm{~S}$ may inflict severe damages on both the environment and industrial equipments.

Hydrogen sulfide is a familiar impurity in natural gas streams, coal gas and chemical feed stocks (Niu et al. 2012; Rao et al. 2012; Zhang et al. 2013). Sulfur compounds in fuels such as methane gas cause problems in two ways: they release toxic gases during combustion, and they damage metals and catalysts in engines and fuel cells (Hazrati et al. 2014). Because of the fact that it is a

\footnotetext{
* To whom correspondence should be addressed
} 
very hazardous, toxic, corrosive and pyrophoric gas, $\mathrm{H}_{2} \mathrm{~S}$ removal has been unavoidably studied applying various methods. Methods of sulfur compounds removal from sour gas, sour oil and furnace exhaust gases have been studied for over 150 years. Early ideas for sour gas, oil and flue gas desulfurization were established in England around 1850 (Niu et al. 2012), one of the most well-known of which is absorption. In this process, sulfur compounds are removed using a liquid treatment that absorbs the sulfur from natural gas, but this process is cumbersome and requires that the gas be cooled and reheated (Wu et al. 2003). To solve these problems, researchers have turned to solid metal oxide adsorbents and some studies have found that sulfur adsorption works best at the surface of solid metal oxides (Balouria et al. 2013). Hydrotreaters now occupy a central role in modern refineries and more than $50 \%$ of all refinery streams (Topsoe et al. 1996; Habibi et al. 2010). Hydro-desulfurization is the largest application of catalytic technology in terms of the volume of processed material (Ma et al. 1994). Commercial hydrotreating catalysts are, typically, molybdenum and zinc. Molybdenum, known for its high hydrogenation activity, is preferred as a promoter when feed stocks containing high amounts of nitrogen and aromatics need to be processed. Despite the solid metal adsorbents work at higher temperatures and eliminate the necessity to cool and reheat the fuel, they lose their activity after only a few cycles of use (Christoforidis et al. 2012). Therefore, the metal adsorbents performance is limited by stability issues. So, the authors have set out to create a material with maximum surface area. The solution seemed to be tiny grains of metal oxide nanoparticles, uniting high surface area, high reactivity, and structural integrity in a high-performance sulfur compounds adsorbent. Apparently, nanoparticles such as metal oxides can promote the heating and cooling process. The nanosubstances can also enhance the thermal stability of some of materials (Novochimskii et al. 2004; Habibi et al. 2009).

In spite of the interesting catalytic properties of molybdenum oxide, a very limited number of studies have been conducted examining the potential of $\mathrm{MoO}_{2}$ as an adsorbent for sweetening processes (Flores et al. 2010; Ellefson et al. 2012; Katrib et al. 1996). Such studies were carried out using commercial $\mathrm{MoO}_{2}$, with particle sizes in the range of a few micrometers and BET surface areas $<10 \mathrm{~m}^{2} / \mathrm{g}$. Molybdenum oxide $\left(\mathrm{MoO}_{2}\right)$ is a transition metal oxide that has long been known to be active for hydrocarbon decomposition and recently has shown high reforming activity for various long-chain hydrocarbons (Ellefson et al. 2012; Katrib et al. 1996). Researchers have shown that $\mathrm{MoO}_{2}$ is highly active for reforming isooctane via partial oxidation (Ellefson et al. 2012; Katrib et al. 1996). This process is exothermic $\left(\Delta \mathrm{H}^{\circ}=-659.9 \mathrm{~kJ} / \mathrm{mol}\right)$ and in the presence of $\mathrm{MoO}_{2}$ proceeds to full conversion at $700{ }^{\circ} \mathrm{C}$ and $1 \mathrm{~atm}$. The catalytic activity shown by $\mathrm{MoO}_{2}$ can be explained in terms of the Marsvan Krevelen mechanism, which involves the consumption of nucleophilic oxygen ions provided by the oxygen sub-lattice with the purpose of sustaining the redox cycles taking place on the adsorbent surface. By utilizing nanoparticles, it has been shown that it is possible to significantly increase the total reactive surface area and thus achieve reforming processes with much higher efficiency levels than those of commercial $\mathrm{MoO}_{2}$. Under similar environments, commercial low surfacearea $\mathrm{MoO}_{2}$ quickly deactivates due to coke formation and sulfur poisoning (Flores et al. 2010). This work is devoted to using experimental design methodology to identify the effect of distinct morphologies of spherical and cylindrical nano- $\mathrm{MoO}_{2}$ on $\mathrm{H}_{2} \mathrm{~S}$ adsorption from a gas stream. The adsorption process variables such as temperature, pressure, nanoparticle sizes, space velocity and $\mathrm{H}_{2} \mathrm{~S}$ feed concentration are also evaluated. The adjustable parameters of Langmuir and Freundlich isotherms are obtained from regression of experimental data and model prediction. The results can be interesting for related industries and can be applicable in process optimization as well as a feasibility point of view.

\section{MATERIALS AND METHOD}

Figure 1 shows the gas sweetening experimental set up. One laboratory cylindrical vessel equipped with a nano-molybdenum oxide fixed bed $(10 \mathrm{~cm}$ diameter and $19 \mathrm{~cm}$ length) was applied for the $\mathrm{H}_{2} \mathrm{~S}$ adsorption process. All equipment's were made of stainless steel since it is a less-corrosive material. A sour methane feed tank containing $\mathrm{H}_{2} \mathrm{~S}$ and methane gas was used and the flow rate was adjusted by two valves. After passing a filter and an electrical heater, the sour gas stream passed through a compressor. The process temperature was adjusted by the electrical heater and an adiabatic protection surrounded the reactor to keep the bed at the experimental temperature, steadily. The gas was compressed and passed through a filter again and then was fed into the reactor with an adjusted flow rate.

$\mathrm{MoO}_{2}$ Nanoparticles were synthesized by reduction of molybdenum trioxide $\left(\mathrm{MoO}_{3}\right)$ powder in a 1:3 volume ratio of ethylene glycol to distilled water (Flores et al. 2010). The mixture was combined in a $45 \mathrm{ml}$ Teflon-lined generalpurpose vessel, which was subsequently sealed and heated to $180^{\circ} \mathrm{C}$ for $12 \mathrm{~h}$. After cooling, the dark colored $\mathrm{MoO}_{2}$ was filtered and air dried at $100^{\circ} \mathrm{C}$. Changing the operating conditions in the synthesis of molybdenum oxide caused different structures of this metal oxide.

The method for production of amorphous spherical and cylindrical $\mathrm{MoO}_{2}$ nanoparticles is using ultrasonic radiation at ambient temperature and pressure by an ultrasonic vacuum chamber during synthesis. In sonication synthesis, the size and shape of nanoparticles can be controlled without affecting the properties of the material. Nanostructured molybdenum particles prepared in this way, 


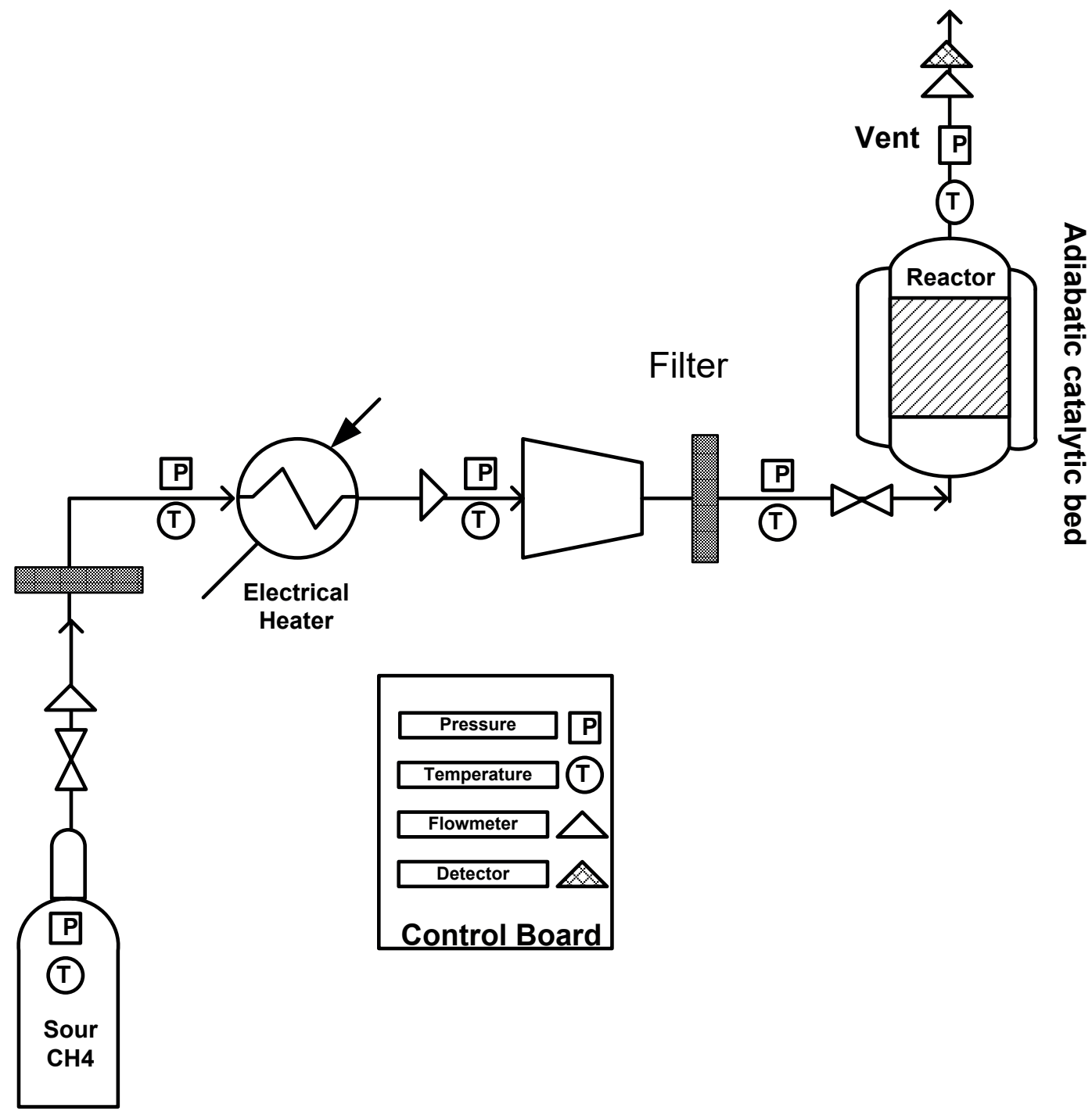

Figure 1. Schematic diagram of the experimental set up.

formed grain sizes which were easily discernable by XRD upon drying. The simplest and most widely used method for estimating the average nano-size particles is using the Scherrer equation (Kaeble, 1967). Using ultrasonic vacuum photoelectron spectroscopy with low energy ion scattering 400-600 watt and 20-30 min exposure time to the ultrasound, spherical nanoparticles were generated. While, when the exposure time was between 30-40 min, cylindrical nanoparticles were produced.

The crystal structure studies of the solids were carried out by a Rigaku Geigerflex x-ray diffractometer using a $\mathrm{Cu}$ $\mathrm{K}_{\alpha}(\lambda=1.5418 \dot{\mathrm{A}})$ radiation source with a nickel filter. Also the particle size and morphology of the particle samples were examined using both SEM (FEI Sirion operated at $15 \mathrm{kV}$ ) and TEM (Philips CM-200 kV). BET surface area measurements were performed using a multipoint micrometrics $2100 \mathrm{E}$ machine.

\section{RESULTS AND DISCUSSION}

In this study, experiments are held to evaluate the effect of process operating and geometrical conditions of the nanoparticles and also nanoparticle diameter on the process performance. The ratio of the $\mathrm{H}_{2} \mathrm{~S}$ final concentration to the initial concentration of $\mathrm{H}_{2} \mathrm{~S}$ is considered as the criteria of the performance quality of the sweetening process. Experimental results are presented in this section and the optimum conditions which lead to the higher performance quality can be surveyed by analyzing the experimental data.

\section{Adsorbent characterization}

Figures 2(a-b) and 2(c) show scanning electron microscope (SEM) and transmission electron microscope 

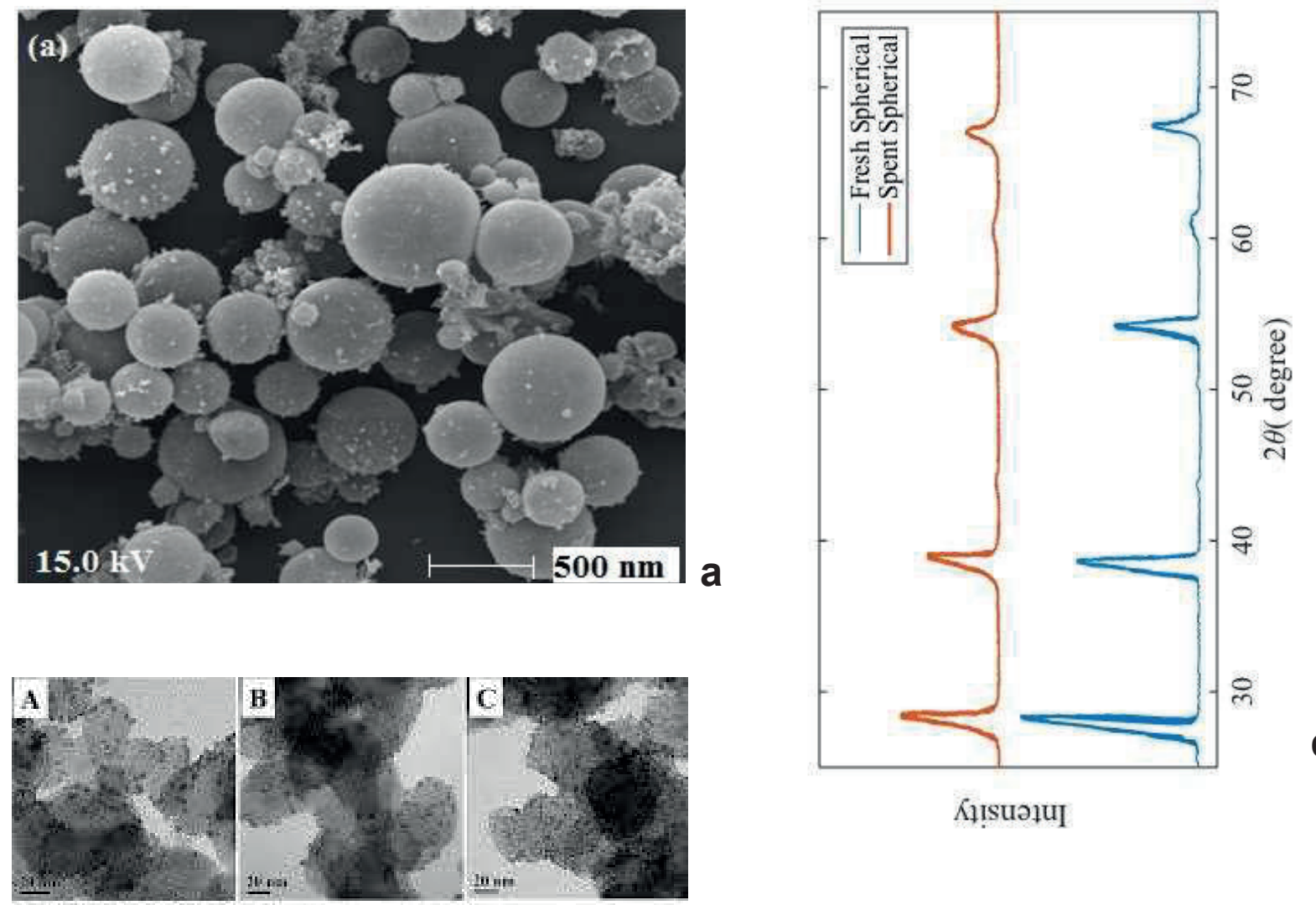

\section{a}
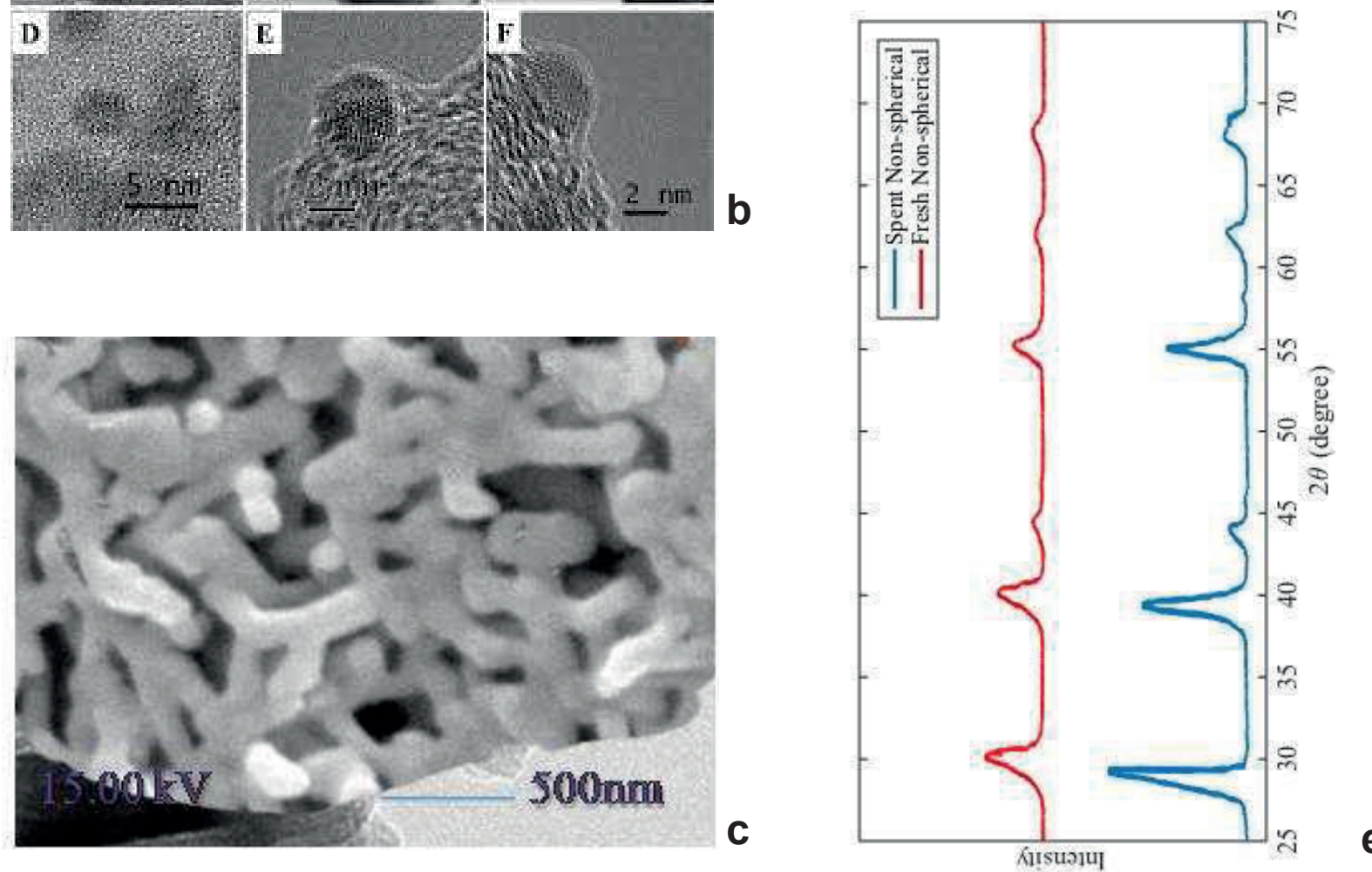

Figure 2. (a) The SEM image of synthesized spherical molybdenum oxide nano particles; (b) cylindrical molybdenum oxide; (c) The TEM images of molybdenum oxide nanoparticles (A, B and C) cylindrical type. D, E and F spherical type molybdenum oxide nanoparticles; (d) XRD patterns of nano molybdenum catalysts before and after $\mathrm{H}_{2} \mathrm{~S}$ adsorption (line a) spherical like fresh nano- $\mathrm{MoO}_{2}$, (line b) spherical like nano- $\mathrm{MoO}_{2}$ after sweetening process; (e) XRD patterns of nano molybdenum catalysts before and after $\mathrm{H}_{2} \mathrm{~S}$ adsorption (line c) cylindrical like fresh nano- $\mathrm{MoO}_{2}$, (line d) cylindrical like nano- $\mathrm{MoO}_{2}$ after adsorption. 
(TEM) images of nanoparticle $\mathrm{MoO}_{2}$, respectively. These images indicate that the agglomerates consist of nanoparticle $\mathrm{MoO}_{2}$ produced with the average diameter of $54-83 \mathrm{~nm}$. By utilizing nanoparticles it is possible to significantly increase the total surface area, a much more uniform particle size and shape, consisting of equiaxial particles with average size of about $20 \mathrm{~nm}$. Figures 2(d) and 2(e) depict the XRD of synthesized molybdenum oxide nanoparticles. These Figures show X-ray diffraction patterns obtained from both the spherical and cylindrical $\mathrm{MoO}_{2}$. In both cases, only the peaks for the distorted rutile structure of the $\mathrm{MoO}_{2}$ phase are present. The most intense peak for the nano-spherical $\mathrm{MoO}_{2}$ and nano-cylindrical $\mathrm{MoO}_{2}$ is at $2 \theta=35^{\circ}$ and $2 \theta=38^{\circ}$, respectively. It is well worth noting that, there are important differences among the diffraction patterns of spherical and cylindrical nanoparticles as shown in Figures 2(d) and 2(e). Figure 2(d) shows that nano- $\mathrm{MoO}_{2}$ sorbent with spherical morphology could remove $\mathrm{H}_{2} \mathrm{~S}$ better than nano-cylindrical $\mathrm{MoO}_{2}$ and it can be indexed exclusively to $\mathrm{MoS}_{2}$ (this was confirmed by $\mathrm{XRD}$, which showed different peaks for $\mathrm{MoS}_{2}$ in spherical type). Moreover, it can be seen from these Figures that the intensity of $\mathrm{MoO}_{2}$ peaks after $\mathrm{H}_{2} \mathrm{~S}$ adsorption decreased while a combination of metal oxides and metal sulfides is formed. These results verify that some crystalline structural changes have occurred after $\mathrm{H}_{2} \mathrm{~S}$ adsorption.

\section{The effect of operating temperature and pressure}

Both, temperature and pressure are two important parameters in separation processes. The changes in the operating pressure and temperature on the performance quality are illustrated in Figures 3 and 4. The feed stream contains $58 \mathrm{ppm}$ of $\mathrm{H}_{2} \mathrm{~S}$. Operating pressure were changed in values of 10,13,16 and 19 bar and operating temperature were varied in values of $65,75,85,87$ and $89^{\circ} \mathrm{C}$ considering to the usual conditions in the adsorption reaction of $\mathrm{H}_{2} \mathrm{~S}$, strength of equipment and safety regulations in the laboratory. Two types of cylindrical and spherical shape nanoparticles with $77 \mathrm{~nm}$ in diameter were applied in the adsorption bed. According to Figure 3, the increment in the operating pressure, increased the process quality at 65 and $75^{\circ} \mathrm{C}$ and at all pressure values, generally using cylindrical type. However, this trend changed for 13 bar and $89^{\circ} \mathrm{C}$, 16 bar and 85,87 and $89{ }^{\circ} \mathrm{C}$. As the temperature at the applied pressure increased a reduction in diffusivity of $\mathrm{H}_{2} \mathrm{~S}$ in the $\mathrm{MoO}_{2}$ pores and product layer was expected. The observed result is in accordance with the reports given by Navochinskii et al. So, $89^{\circ} \mathrm{C}$ and temperatures higher than $85^{\circ} \mathrm{C}$ are not proper operating temperatures at 13 bar and 16 bar, respectively. Also, an increase in the pressure value from 13 bar to 16 bar showed the considerable decrease in the value of $C / C_{0}$. The higher pressures $16 \mathrm{bar}$ and 19 bar present lower value of $C / C_{0}$ at the higher temperature. So, the case of determination of the minimum values of energy consumption can be discussed here. However, considering the strength of the reactor vessel, the higher temperatures $\left(87,89^{\circ} \mathrm{C}\right)$ result in a better value of $C / C_{0}$ at lower pressures of 10 bar and 13 bar.

Operating conditions of 16 bar and $85{ }^{\circ} \mathrm{C}$ can be introduced as the optimum operating conditions in the experiments. This is determined due to the marketing standard value of $\mathrm{H}_{2} \mathrm{~S}$ in the sweet gas stream which is lower than $4 \mathrm{ppm}$, i.e., $3.54 \mathrm{ppm}$ at 16 bar and $85^{\circ} \mathrm{C}$.

Figure 4 shows the changes in the values of $C / C_{0}$ according to the changes in the operating temperature and pressure using spherical nano- $\mathrm{MoO}_{2}$. The lower values of $C / C_{0}$ were obtained at higher temperatures and constant pressure. The increase in the pressure value from 13 bar to 16 bar decreased the value of $C / C_{0}$ considerably, comparing with the changes from 10 to 13 bar or 16 to 19 bar. The higher pressure values resulted in lower values of $C / C_{0}$ using 75 and $85^{\circ} \mathrm{C}$; however, this was not obtained at temperatures higher than $85^{\circ} \mathrm{C}$ initializing the operating pressure of 16 bar and 19 bar. This might be related to the effective operating pressure of the gas stream in the nanoparticle bed, which provides the proper effective gas diffusion into the adsorbent at the adjusted temperature.

\section{The effect of nanoparticle diameter}

In this section, nano-molybdenum oxide adsorbents with five different diameters are applied in separate experiments. The changes in the diameter of nanoparticles affect the value of $C / C_{0}$ as shown in Figures 5 and 6 using spherical and cylindrical nanoparticles, respectively. According to the results which were obtained above, the optimum operating temperature, $85^{\circ} \mathrm{C}$, and pressure 16 bar were considered in the experiments. At the optimum pressure 16 bar and temperature of $85^{\circ} \mathrm{C}$ in the adsorbent bed with length of $3 \mathrm{~cm}$ and $8 \mathrm{~cm}$ diameter included spherical nanoparticle, the changes in the value of $C / C_{0}$ were investigated with various particle diameters, 54, 58, 73,77 and $83 \mathrm{~nm}$. The ratio of the bed diameter on the bed length was relatively large (2.67) and assumed to provide proper distribution and reaction surface area, avoiding channeling. However, changes in particle diameter showed considerable effect on the value of $C / C_{0}$ for both spherical and cylindrical nanoparticles, even in this provided bed.

While it appears to be an oscillatory trend, Figures 5 and 6 show that there is a higher value of $C / C_{0}$ using larger nanoparticles in diameter on the whole. This might be related to the larger effective surface area provided by the smaller nanoparticles in the specified geometry of the bed. The smaller particles also form a thinner gas boundary layer around the particles, which is responsible for convective mass transfer in the gas phase. Smaller particles make diffusion mass transfer faster and so molybdenum oxide with smaller nanoparticles improves the adsorption capacity, which must be the result of more surface area. 


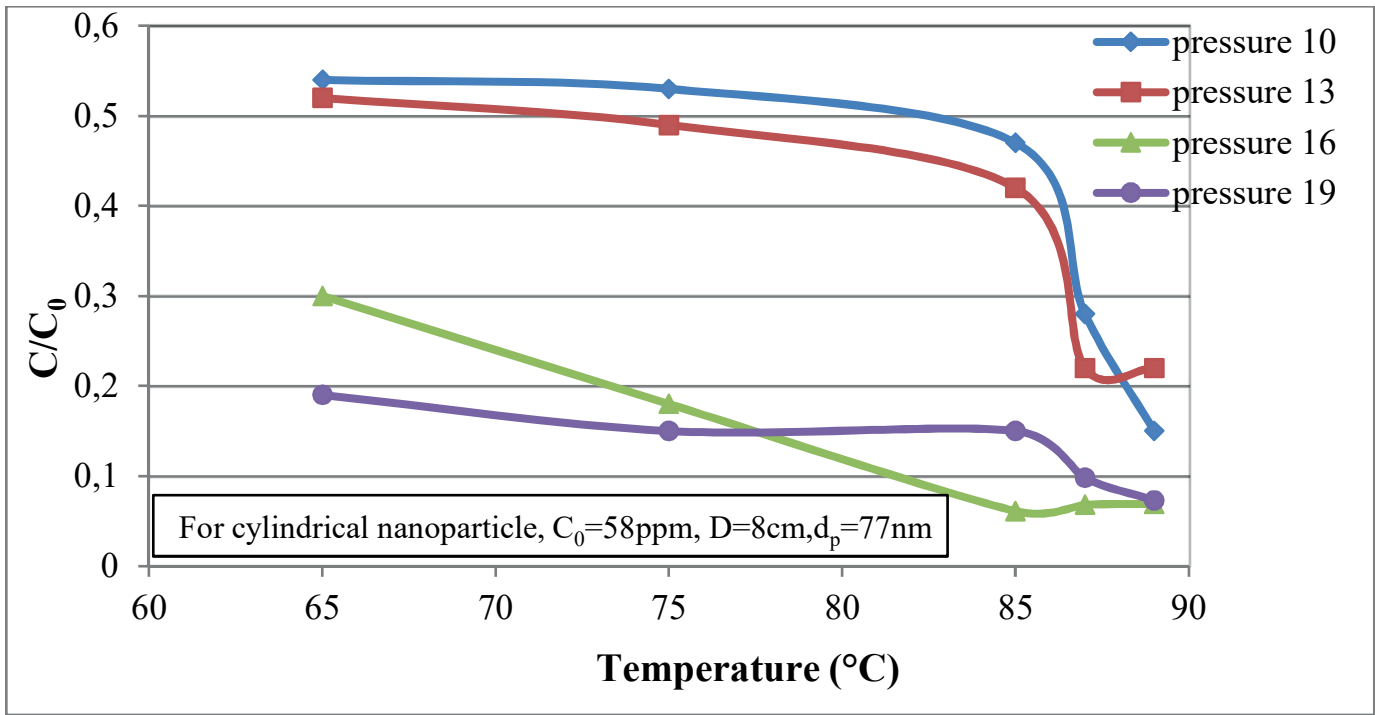

Figure 3. Performance quality versus operating conditions using cylindrical nano adsorbent

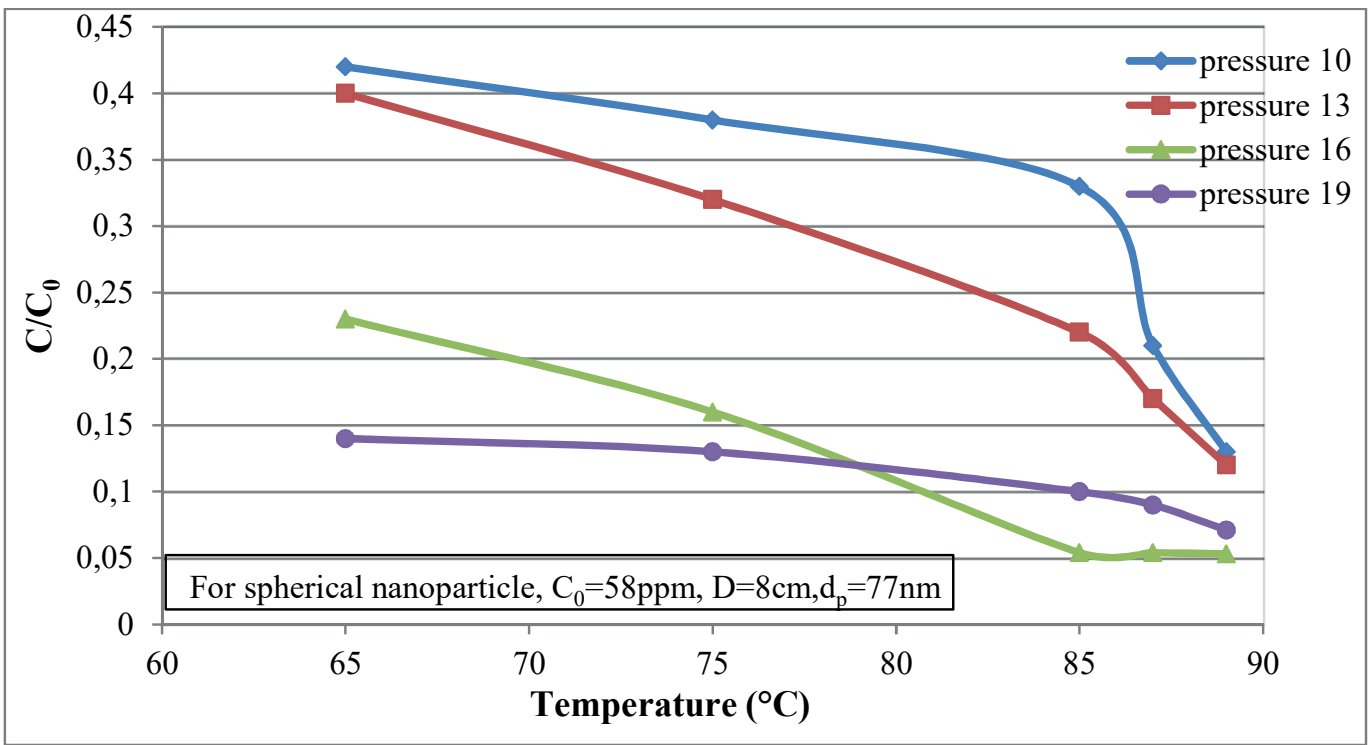

Figure 4. Performance quality versus operating conditions using nano-spherical adsorbent

Considering the most important part of our study, which was studying the influence of sorbent morphology on $\mathrm{H}_{2} \mathrm{~S}$ adsorption, the morphology of spherical and cylindrical sorbents was characterized using the dynamic capacity of $\mathrm{H}_{2} \mathrm{~S}$ removal $\left(C / C_{0}\right)$. Comparing the results from Figure 5 and Figure 6 shows that the spherical and cylindrical type of nanoparticle $58 \mathrm{~nm}$ in diameter had the lowest value of $C /$ $C_{0}$ of about 0.032 and 0.044 , respectively. This may relate to the proper arrangement of spherical geometry compared with the cylindrical geometry in the defined dimensions of adsorbent bed. It is noticeable that the range of dynamic $\mathrm{H}_{2} \mathrm{~S}$ adsorption capacity of $\mathrm{MoO}_{2}$ was $0.025-0.22 \mathrm{~g} \mathrm{H}_{2} \mathrm{~S} / \mathrm{g}$
$\mathrm{MoO}_{2}$. Besides, the BET results indicated that the surface areas of cylindrical and spherical nano- $\mathrm{MoO}_{2}$ were 10 and $48 \mathrm{~m}^{2} / \mathrm{g}$, respectively, which were about an order of magnitude greater than that of the commercially available material (Flores et al. 2010). High surface area was also beneficial for adsorbents as more active sites per volume allow for greater adsorbed flow rates and more efficient adsorption. This result is consistent with the observation given in Sekhavatjou et al. (2014) that, with reduction of iron oxide particle size (from $0.14 \mu \mathrm{m}$ to $20 \mathrm{~nm}$ ), the sulfur removal rate increased from 37.9 to $63.1 \%$ in all of the natural gas components. 


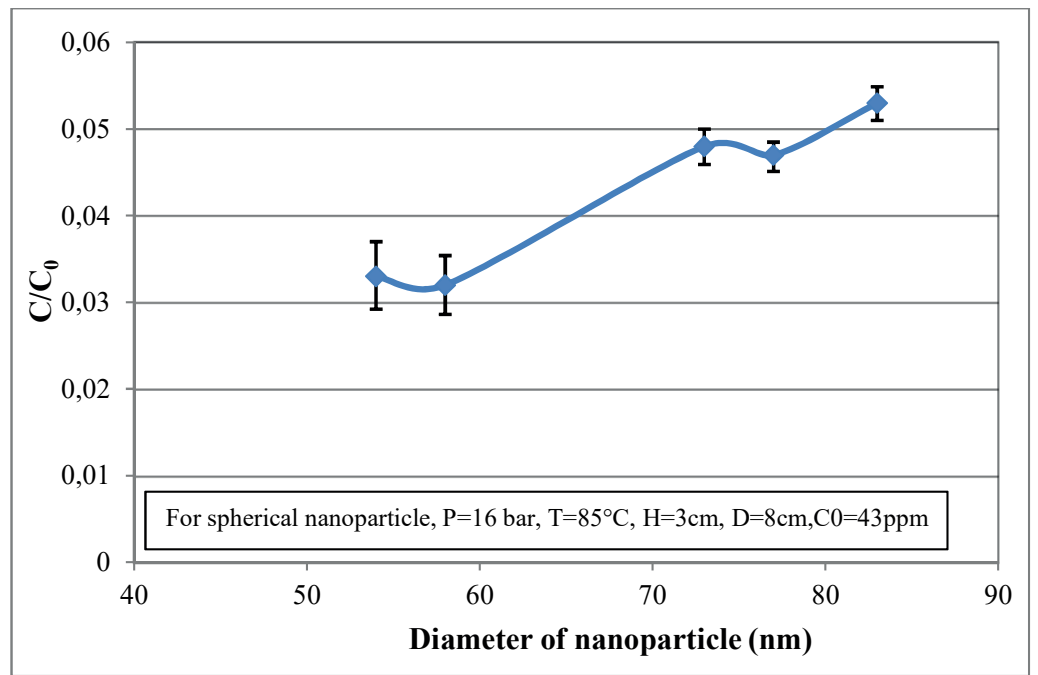

Figure 5. Performance quality versus particle diameter for spherical adsorbent

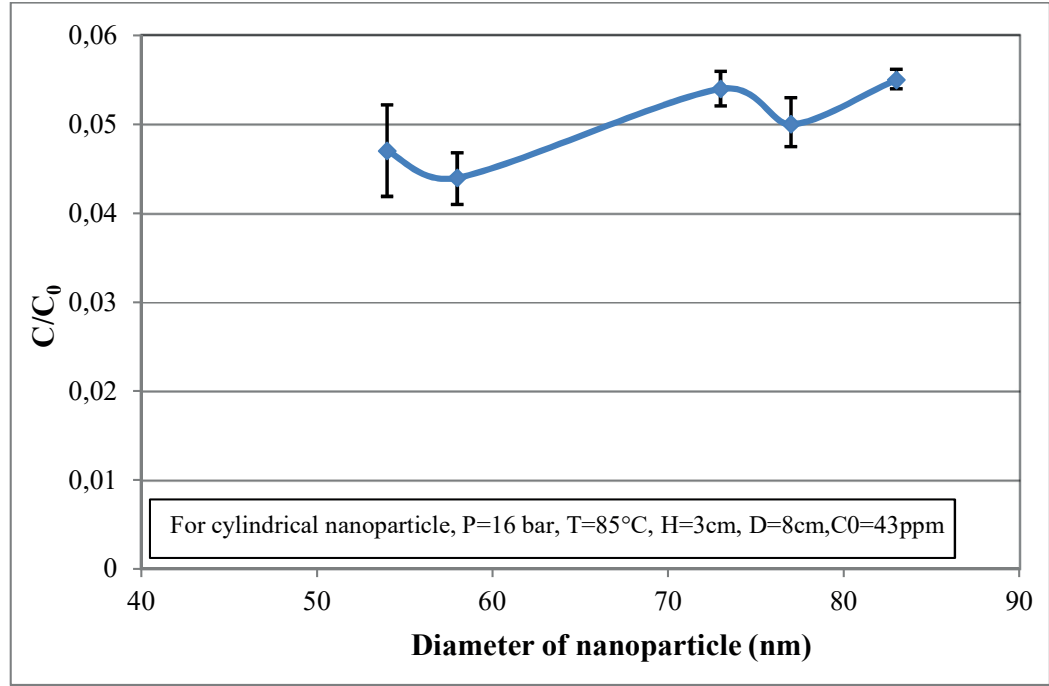

Figure 6. Performance quality versus particle diameter for cylindrical adsorbent.

\section{The effect of initial concentration}

The initial concentration of $\mathrm{H}_{2} \mathrm{~S}$ contaminant in the feed stream provided the driving force for the adsorption reaction. Applying optimum operating conditions of 16 bar and $85{ }^{\circ} \mathrm{C}$ for cylindrical and spherical type nanomolybdenum oxide and optimum diameter of $58 \mathrm{~nm}$ for both spherical and cylindrical type, the effect of driving force on the adsorption reaction is investigated in Figures 7 and 8 .

In each run, a feed stream containing a different concentration of $\mathrm{H}_{2} \mathrm{~S}(38,43,58,64$ and $73 \mathrm{ppm})$ was passed through the bed and the performance quality of the adsorption process was investigated. The performance of the spherical type of nanoparticle did not show any considerable changes using different initial concentrations from $38 \mathrm{ppm}$ to $64 \mathrm{ppm}$ and all the obtained values were in

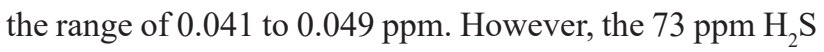
concentration showed a sudden increase in the value of $C$ / $C_{0}$. So, it can be concluded that, for the spherical type of nanoparticle, the effect of initial driving force in the feed stream is not considerable until the concentration of $\mathrm{H}_{2} \mathrm{~S}$ of $73 \mathrm{ppm}$ in the feed stream.

Figure 8 shows the considerable effect of initial driving force on the value of the adsorption capacity using cylindrical nanoparticle. The changes in $\mathrm{H}_{2} \mathrm{~S}$ content in the feed gas from $38 \mathrm{ppm}$ to $73 \mathrm{ppm}$ gave values of 0.047 to 0.071 for the value of $C / C_{0}$. This indicates that the capacity of nanoparticles is fixed and the active surface site reduction provides a more reasonable explanation for this behavior. So the quality of the adsorption process of $\mathrm{H}_{2} \mathrm{~S}$ on cylindrical adsorbent is sensitive to the initial concentration of contaminant in comparison with the spherical type. 


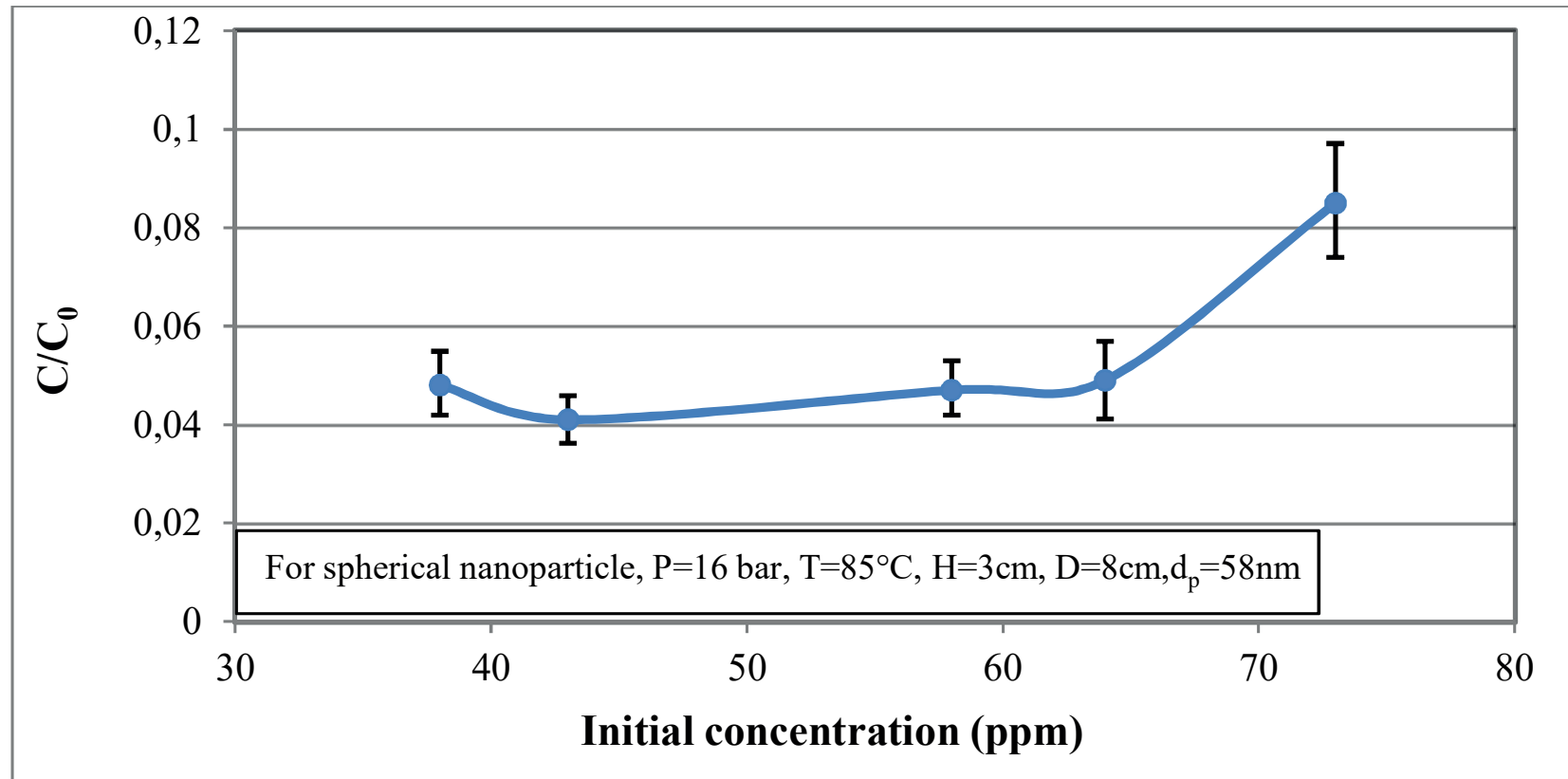

Figure 7. Performance quality versus initial concenration for spherical type

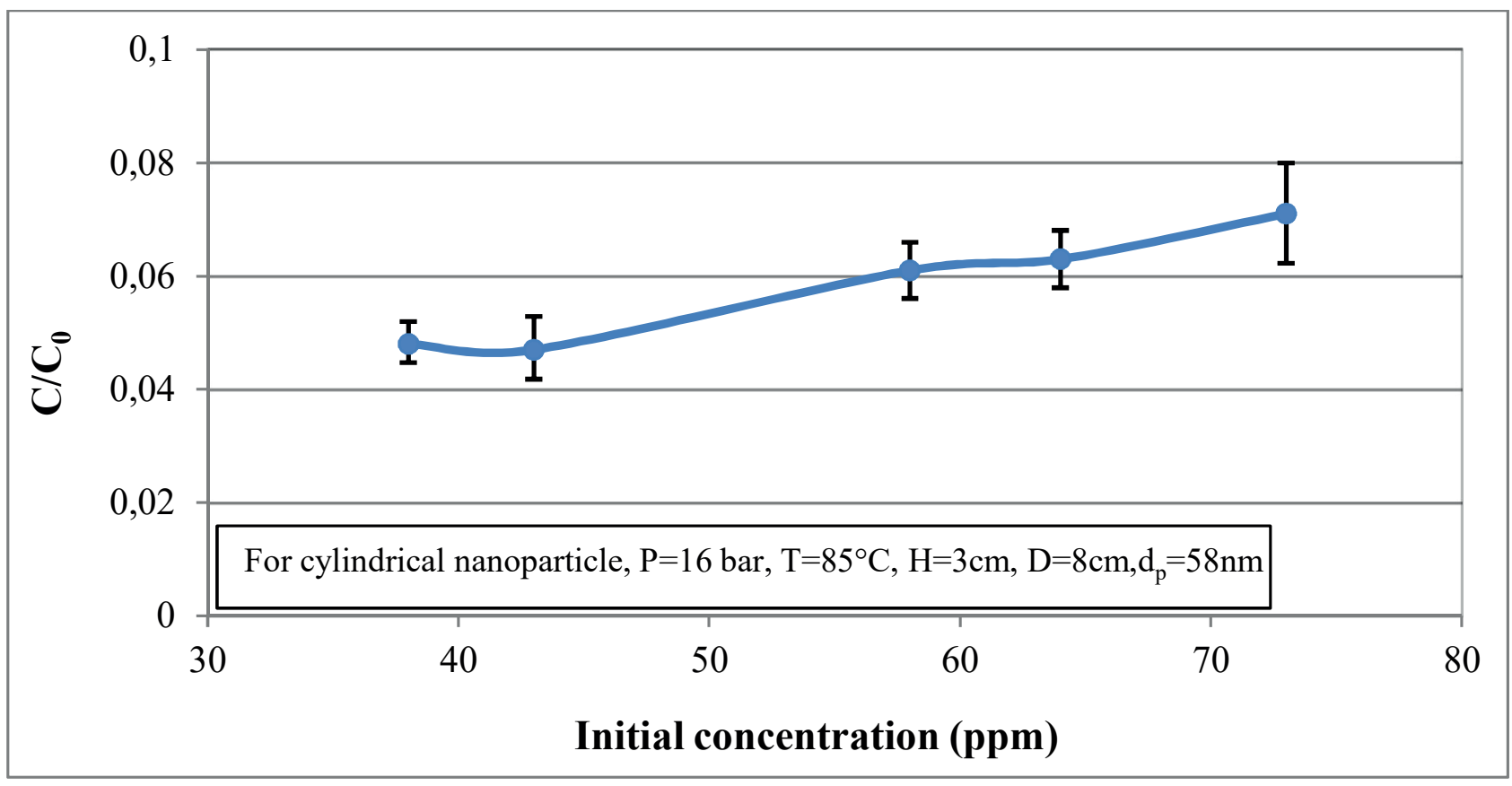

Figure 8. Performance quality versus initial concenration for cylindrical type

\section{The effect of feed superficial velocity}

To determine the effect of feed superficial velocity, this parameter was studied in the range of 0.018-0.045 $\mathrm{m} / \mathrm{s}$. As is expected, the higher the superficial velocity the less the dynamic $\mathrm{H}_{2} \mathrm{~S}$ adsorption capacity will be. Lower superficial velocity values provided more time for $\mathrm{H}_{2} \mathrm{~S}$ component to reach the surface of fresh $\mathrm{MoO}_{2}$ uncovered with $\mathrm{MoS}_{2}$. Figure 9 shows that, with the rise in superficial velocity, a higher content of input $\mathrm{H}_{2} \mathrm{~S}$ emerges from the bed and the value of $C / C_{0}$ increases for both spherical and cylindrical nanoparticles. The results were obtained in the aforementioned optimum conditions for spherical and cylindrical nanoparticles. 


\section{The effect of bed length}

The length of the adsorption bed was changed between $4 \mathrm{~cm}$ and $7 \mathrm{~cm}$. The optimum length of the nano-sorbent bed was studied in this section. According to Figure 10, the increment in the bed length improves the $\mathrm{H}_{2} \mathrm{~S}$ removal for both cylindrical and spherical nanoparticles. However, a slight decrease in the value of $C / C_{0}$ was obtained at a length more than $6 \mathrm{~cm}$. So using extra adsorption bed longer than $6 \mathrm{~cm}$ did not have a considerable effect on $\mathrm{H}_{2} \mathrm{~S}$ removal.

\section{Equilibrium mechanism of adsorption}

Two adsorption isotherms, Langmuir and Freundlich isotherms are proposed to fit the experimental data. Table 1 demonstrates the isotherms equations used in our study. As can be seen from Figures 11 and 12, the values of the coefficients of determination $\left(\mathrm{R}^{2}\right)$ for spherical nanoparticles are 0.969 and 0.989 for Langmuir and Freundlich isotherms, respectively. Being close to 1, the value of $\mathrm{R}^{2}$ for the Freundlich isotherm ensures the

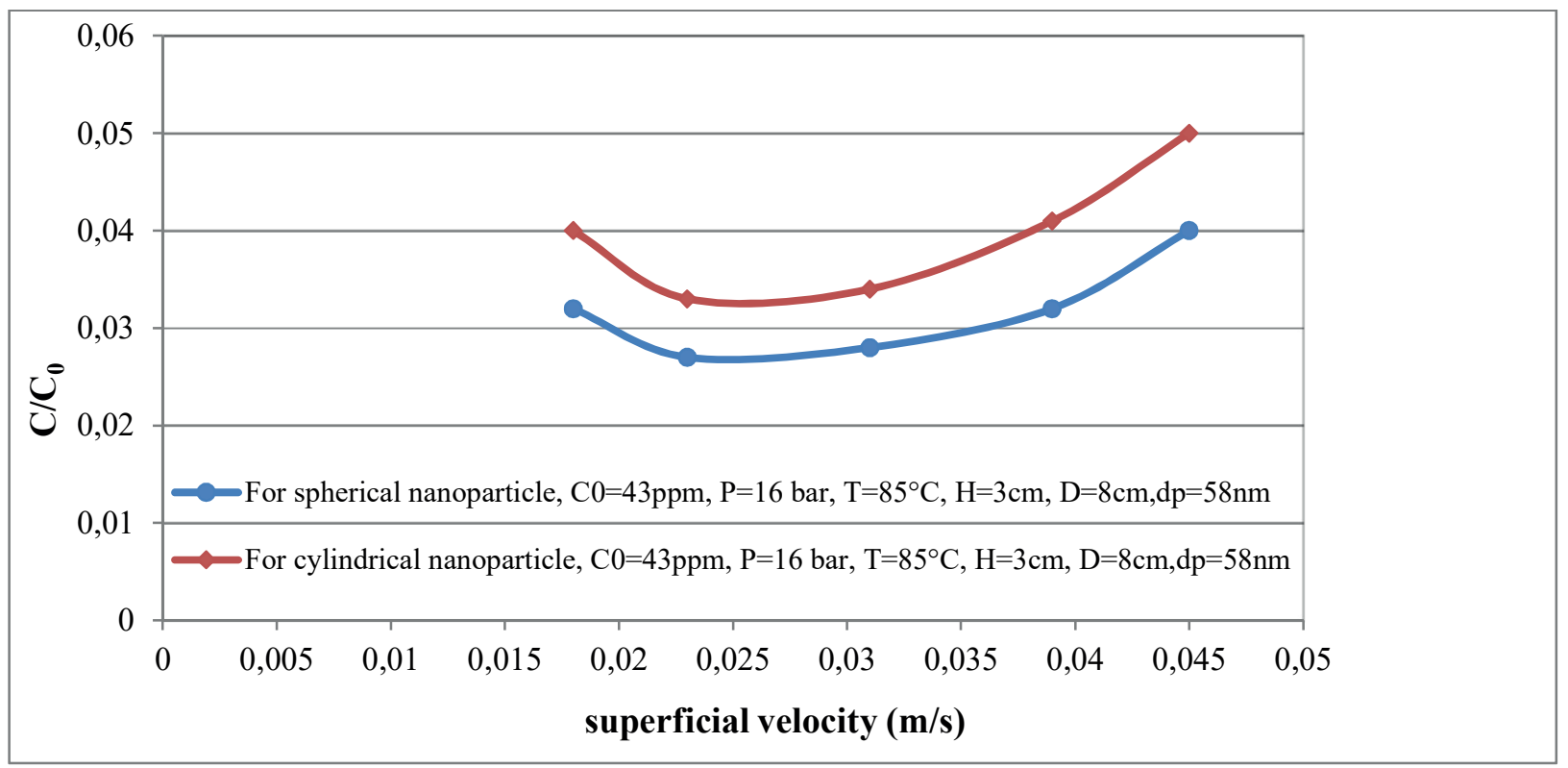

Figure 9. Performance quality versus feed superficial velocity

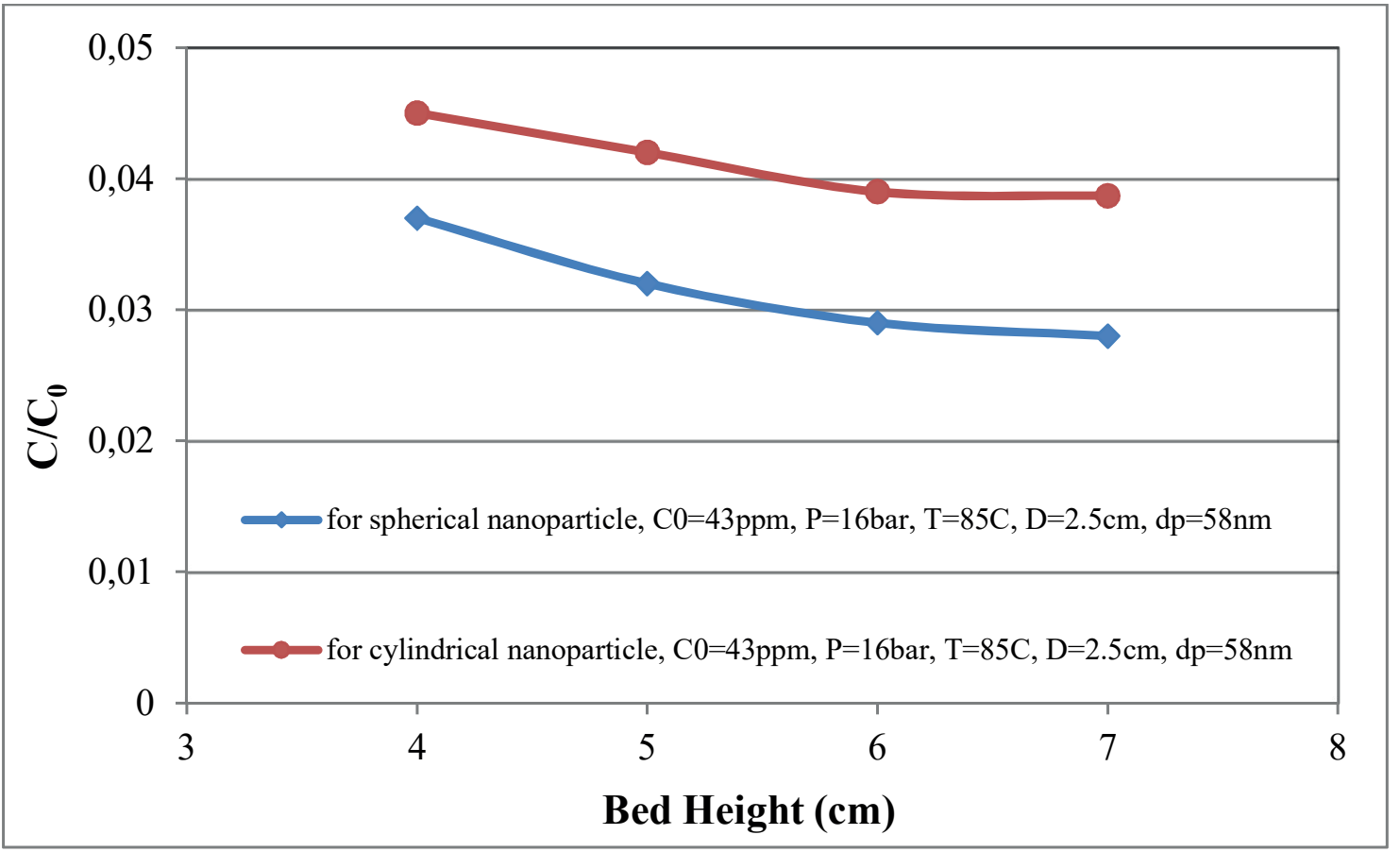

Figure 10. Performance quality versus molybdenum oxide bed height 


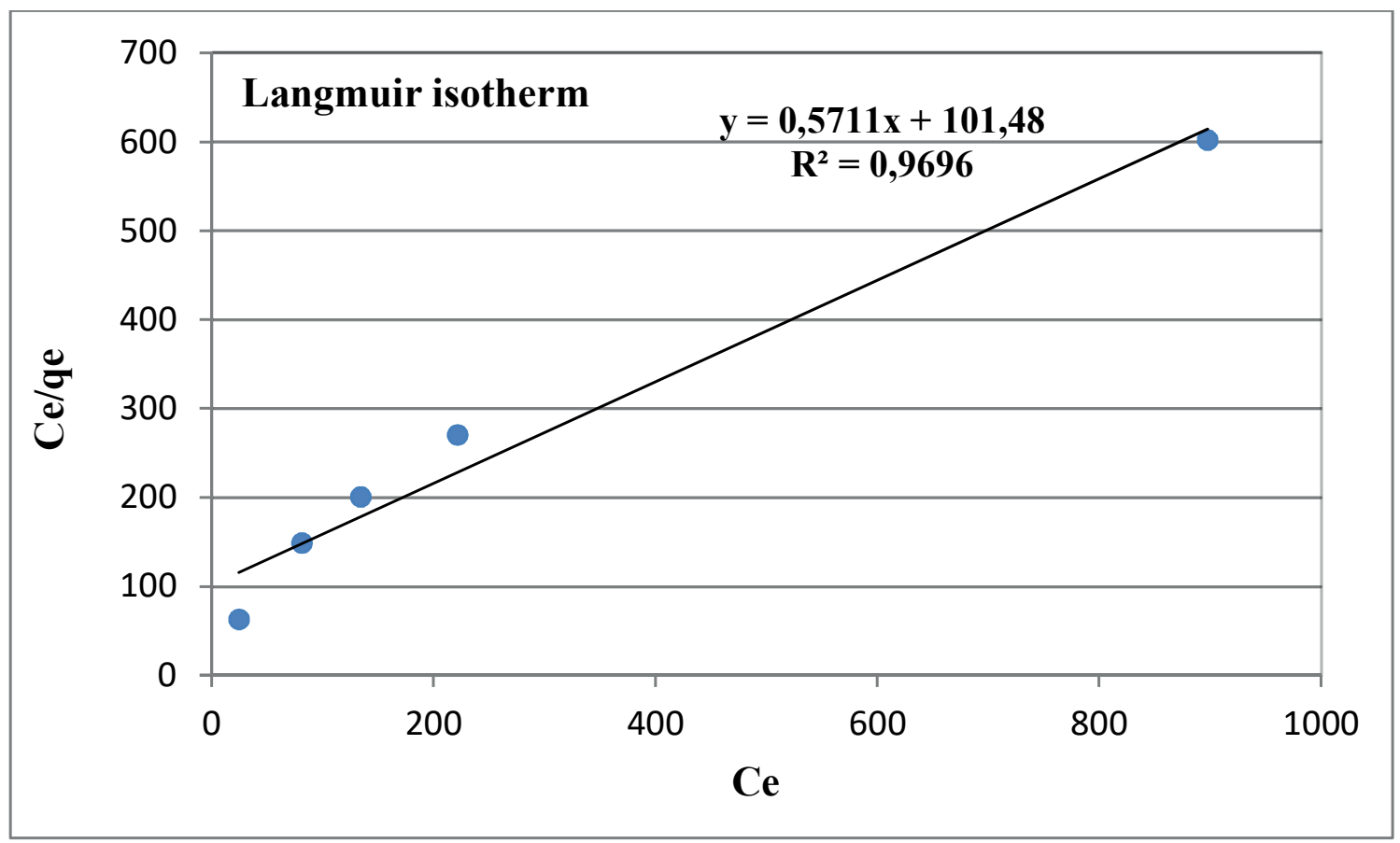

Figure 11. Correlation the experimental data with a Langmuir isotherm for spherical nanoparticles

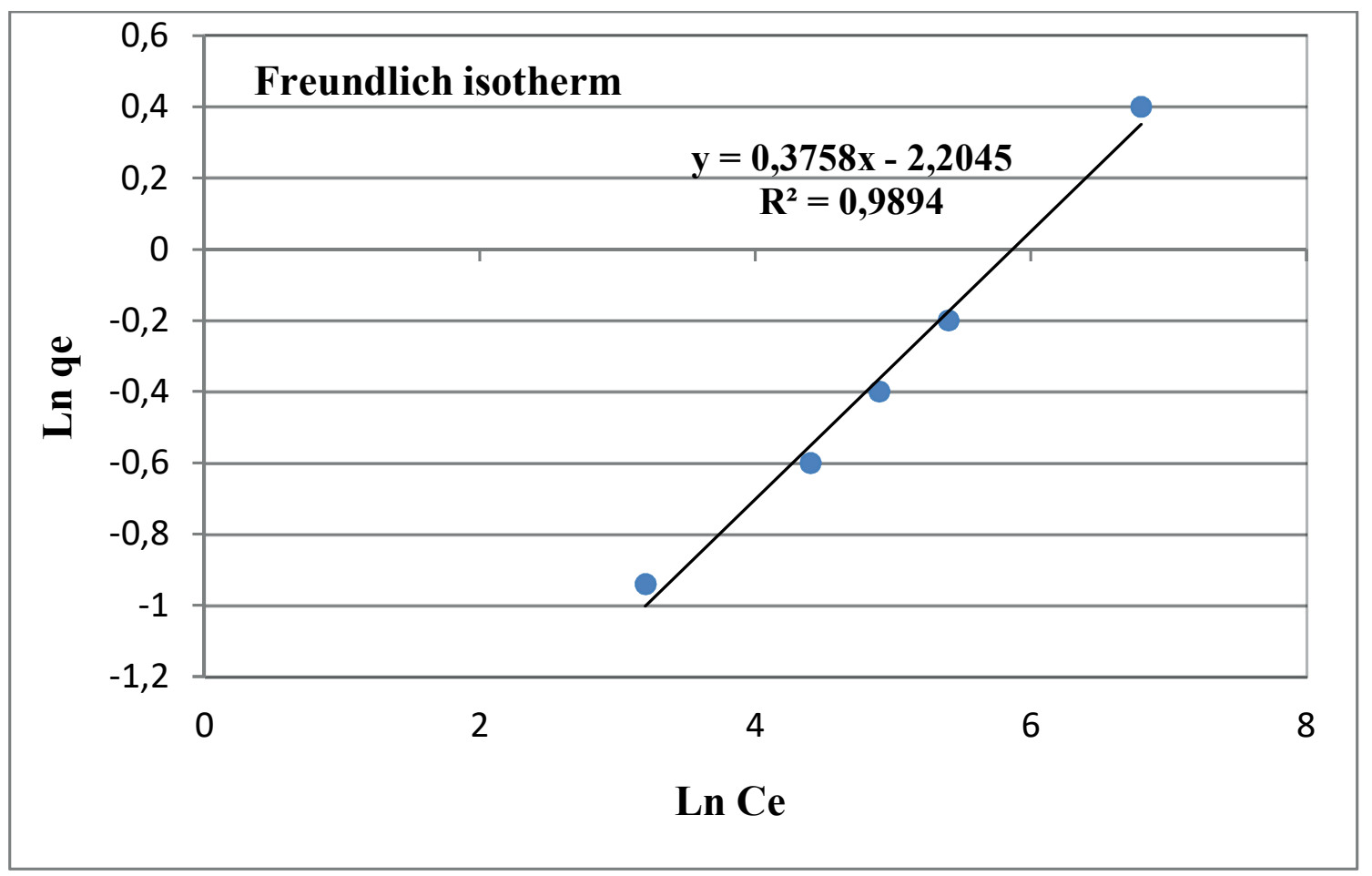

Figure 12. Correlation the experimental data with a Freundlich isotherm for spherical nanoparticles

perfectness of the correlation between the predicted and observed values. Thus, the Freundlich isotherm can predict the adsorption of gases by the solid adsorbent more accurately than the Langmuir isotherm. The deficiency of the Langmuir isotherm is that it considers the equilibrium mechanism of adsorption and desorption of reactants and products uniformly across the adsorbent surface and at high pressures the reaction rate is independent of gas 
pressure and the surface coverage fraction would be unity. This is consistent with results in the literature (Nabipoor Hassankiadeh and Haghtalab, 2013). The above-mentioned adsorption parameters based on the experimental data are presented in Table 2 for both isotherms.

Table 1. Adsorption isotherms of spherical nanoparticles

\begin{tabular}{|c|c|c|}
\hline & Langmuir isotherm & Freundlich isotherm \\
\hline & $\frac{c_{e}}{q_{e}}=\frac{c_{e}}{q_{m}}+\frac{1}{k_{l} q_{m}}$ & $\operatorname{Ln} q_{e}=\operatorname{Ln} k_{f}+\frac{1}{n}\left(\operatorname{Ln} C_{e}\right)$ \\
\hline $\mathrm{R}^{2}$ & 0.969 & 0.989 \\
\hline
\end{tabular}

Table 2. Adsorption parameters of the isotherms

\begin{tabular}{ccccc}
\hline & Langmuir isotherm & \multicolumn{3}{c}{ Freundlich isotherm } \\
\hline Parameter & Value & Unit & Value & Unit \\
$k_{f}$ & - & - & 9.06 & $\mathrm{~L} \mathrm{mg}^{-1}$ \\
$n$ & - & - & 2.67 & - \\
$k_{l}$ & 0.006 & $\mathrm{~L} \mathrm{mg}^{-1}$ & - & - \\
$q_{m}$ & 1.75 & $\mathrm{mg} \mathrm{g}^{-1}$ & - & - \\
$\beta$ & - & - & - & - \\
\hline
\end{tabular}

\section{CONCLUSION}

The performance quality of a gas sweetening process is surveyed in this study. The effect of parameters which are responsible for mass transfer phenomena such as dimensions of adsorbents, shape of nanoparticles and initial driving force are investigated. In addition, the effect of temperature and pressure on the process quality is considered in this work. The main experimental results are presented as follows:

1. The optimum pressure and temperature for both spherical and cylindrical particles are 16 bar and $85^{\circ} \mathrm{C}$. However, the value of $C / C_{0}$ in this optimum condition for the spherical type is 0.054 , lower than that obtained $(0.061)$ using the cylindrical type with the same diameter of $77 \mathrm{~nm}$.

2 . The optimum value of the adsorbent diameter for the spherical and cylindrical types is $58 \mathrm{~nm}$, which gives the values of 0.032 and 0.044 for $C / C_{0}$, respectively.

3. At the optimum operational and dimensional conditions for cylindrical and spherical adsorbents, the initial driving force is not the process controller for the adsorption with the spherical type when the initial concentration of $\mathrm{H}_{2} \mathrm{~S}$ is lower than $64 \mathrm{ppm}$. However, changes in the initial concentration of $\mathrm{H}_{2} \mathrm{~S}$ show gradual and steady changes in the value of $C / C_{0}$ from 0.047 to 0.071 when using the cylindrical type of nanoparticle.

4. The capability of nano-molybdenum oxide adsorbents decreases with an increase in the superficial velocity. Moreover, the optimum bed length is $6 \mathrm{~cm}$ for both cylindrical and spherical nanoparticles, because the value of $C / C_{0}$ decreases slightly at a length larger than 6 $\mathrm{cm}$.

5. Finally, it can be concluded that the Freundlich isotherm is in better agreement with the experimental data than the Langmuir isotherm. Thus, it is possible to predict the $\mathrm{H}_{2} \mathrm{~S}$ removal capacity relying on the Freundlich isotherm.

\section{ACKNOWLEDGMENTS}

We thank Shohreh Hariri for her assistance during preparation of this manuscript. The authors are also appreciative for the financial support from the National Iranian Gas Company (NIGC).

\section{REFERENCES}

Alie, C., Backham, L., Croiset, E., Douglas, P.L., Simulation of $\mathrm{CO}_{2}$ capture using MEA scrubbing: a flow sheet decomposition method, Energy Convers. Manage. 46, 475487 (2005).

Balouria, V., Kumar, A., Samanta, S., Singh, A., Debnath, A.K, Mahajan, A., Bedi, R.K., Aswal, D.K., Gupta, S.K., Nanocrystalline $\mathrm{Fe}_{2} \mathrm{O}_{3}$ thin films for ppm level detection of $\mathrm{H}_{2} \mathrm{~S}$, Sens. Actuators B. 181, 471-478 (2013). 
Christoforidis, K.C., Figueroa, S.J.A., Fernández-García, M., Iron-Sulfur Codoped $\mathrm{TiO}_{2}$ Anatase Nano-Materials: UV and Sun-light Activity for Toluene Degradation, Appl. Catal. B. 18, 310-316 (2012).

Ellefson, C., Flores, O.M., Ha, S., Norton, G., Synthesis and applications of molybdenum (IV) oxide, J. Mater. Sci. 47, 2057-2071 (2012).

Emerson, S.C., Coote, C.F., Boote, H., Tufts, J.C., Larocque, R., Moser, W.R., The ultrasonic synthesis of nanostructured metal oxide catalysts, prep. Catal. 7, 773-785(1998).

Flores, O.M., Turba, T., Ellefson, C., Wang, K., Breit, J., Ahn, J., Nanoparticle molybdenum dioxide: a highly active catalyst for partial oxidation of aviation fuels, Appl. Catal. B. Environ. 98, 186-192 (2010).

Habibi, R., Daryan, J.T., Rashidi, A.M., Shape and size-controlled fabrication of $\mathrm{ZnO}$ nanostructures using novel templates, J. Exp. Nanosci. 4, 35-45 (2009).

Habibi, R., Rashidi, A.M., Daryan, J.T., Alizadeh, A.M., A Study of the rod-like and spherical nano-ZnO morphology on $\mathrm{H}_{2} \mathrm{~S}$ removal from natural gas, Appl. Surf. Sci. 257, 434-439 (2010).

Hazrati, H., Abdouss, M., Vahid, A., Miran Beigi, A.A., Mohammadalizadeh, A., Removal of $\mathrm{H}_{2} \mathrm{~S}$ from crude oil via stripping followed by adsorption using $\mathrm{ZnO} / \mathrm{MCM}-41$ and optimization of parameters, Int. j. Environ. Sci. Technol. 11(4), 997-1006(2014).

Kaeble, E., Handbook of X-Rays, McGraw-Hill, New York, (1967).

Katrib, A., Leflaive, P., Hilaire, L., Maire, G., Molybdenum based catalysts. I. $\mathrm{MoO}_{2}$ as the active species in the reforming of hydrocarbons, Catal. Lett. 38, 95-99 (1996).

Ma, X., Sakanishi, K., Mochida, I., Hydrodesulfurization reactivities of various sulfur compounds in diesel fuel, Ind. Eng. Chem. Res. 33, 218-222 (1994).

Mandal, B.P., Biswas, A.K., Bandyopadhyay, S.S., Selective absorption of $\mathrm{H}_{2} \mathrm{~S}$ from gas streams containing $\mathrm{H}_{2} \mathrm{~S}$ and $\mathrm{CO}_{2}$ into aqueous solutions of $\mathrm{N}$-methyldiethanolamine and 2amino-2- methyl-1- propanol, Sep. Purif. Technol. 35, 191202 (2004)

Nabipoor Hassankiadeh, M., Haghtalab, A., Product Distribution of Fischer Tropsch Synthesis in a Slurry Bubble Column Reactor Based on Langmuir-Freundlich Isotherm, Chem. Eng. Comm. 200 (2013), 1170-1186.

Niu, Y., Xing, M., Tian, B., Zhang, J., Improving the visible light photocatalytic activity of nano-sized titanium oxide via the synergistic effects between sulfur doping and sulfation, Appl. Catal. B. Environ. 5, 253-260 (2012).

Novochimskii, I., Song, C., Ma, X., Liu, X., Shore, L., Lampert, J., Farrauto, R.J., Low temperature $\mathrm{H}_{2} \mathrm{~S}$ removal from steam containing gas mixtures with $\mathrm{ZnO}$ for fuel cell application. 1. $\mathrm{ZnO}$ particles and extrudates, Energy Fuels. 18, 576-583 (2004).

Rao, M., Song, X., Cairns, E.J., Nano-carbon/sulfur composite cathode materials with carbon nano-fiber as electrical conductor for advanced secondary lithium/sulfur cells, J. Power Sources, 205, 474-478 (2012).

Sekhavatjou, M.S., Moradi, R., Hosseini Alhashemi, A., Taghinia Hejabi, A., A new method for sulfur components removal from sour gas through application of zinc and iron oxides nanoparticles, Int. J. Environ. Res. 8, 273-278 (2014).

Topsoe, H., Clausen, B.S., Massoth, F.E., Hydrotreating catalysis, Catalysis-Science and Technology, Springer -Verlag, Berlin, p. 1-3 (1996).

Wu, Q., Yakshinskiy, B.V., Madey, T.E., Adsorption and decomposition of $\mathrm{H}_{2} \mathrm{~S}$ on $\mathrm{UO}_{2}\left(\begin{array}{l}0 \\ 0\end{array}\right)$, Surf. Sci. 523, 1-11 (2003).

Zhang, Y., Zhao, Y., Konarov, A., Gosselink, D., Soboleski, H.G., Chen, P., A novel nano-sulfur/polypyrrole/graphene nanocomposite cathode with a dual-layered structure for lithium rechargeable batteries, J. Power Sources, 241, 517-521 (2013). 